\title{
Evaluation of neuropharmacological activity of dioscorea bulbifera using various experimental models
}

\begin{abstract}
Dioscorea bulbifera commonly known as Varahikanda, is widely distributed throughout the India, and it has been traditionally used for the treatment of nervous excitability, senility and hysteria. Based on this, neuropharmacological activity of tubers of $D$. bulbifera was evaluated using various experimental models. Effects of hydroalcoholic extract of Dioscorea bulbifera tubers (DBE) $(10,30,100,300$, and $1000 \mathrm{mg} / \mathrm{kg}$, p.o.) was tested on behavioral profile of mice. Acute treatment of DBE $(100$ and $300 \mathrm{mg} / \mathrm{kg}$, p.o.) was evaluated for spontaneous motor activity, motor coordination, pentobarbitone induced hypnosis, anxiolytic activity, exploratory activity and body temperature of mice. Phytochemical analysis of DBE indicates presence of terpenoids, saponins, glycosides, flavanoids, alkaloids, carbohydrates and proteins. DBE showed central nervous depressant action in general behavioral tests. The DBE showed significant $(p<0.05)$ reduction of spontaneous motor activity and prolonged the pentobarbitone induced hypnosis in mice. Anxiolytic potential of DBE was observed by the results of elevated plus maze test in which DBE significantly increased number of entries and time spent in the open arms. Further, anxiolytic activity of DBE was confirmed by head-dip test in which exploratory activity of mice was increased significantly. However, DBE had no effect on motor co-ordination as determined by the rota rod test which confirmed central action rather than peripheral action of DBE. Moreover, CNS depressant action of DBE indicated by significant reduction of rectal temperature of mice. The findings of the present investigation indicate that the hydroalcoholic extract of $D$. bulbifera has central nervous depressant/sedative and anxiolytic potential which may be due combined effects of psychoactive principles.
\end{abstract}

Keywords: dioscorea bulbifera, spontaneous motor activity, motor coordination, pentobarbitone induced hypnosis, anxiolytic activity, exploratory activity, dody temperature
Volume 7 Issue I - 2017

\author{
Patel Divyesh M,' Galani Varsha J' \\ 'Department of pharmacology, AR College of Pharmacy \& GH \\ Patel Institute of Pharmacy, India \\ ${ }^{2}$ Department of pharmacology, Indukaka Ipcowala College of \\ Pharmacy, India
}

Correspondence: Galani Varsha J, M.Pharm (Pharmacology), Ph.D, Department of pharmacology, Indukaka Ipcowala College of Pharmacy, New Vallabh Vidyanagar-388 I 2 I, Gujarat, India, Tel $+91-942+916+120+3$, Fax 026+922+297+00, Emailvrp173@yahoo.com

Received: November 19,2016 | Published: April 12, 2017

\section{Abbreviations: DBE (hydroalcoholic extract of tubers of D.bulbifera)}

\section{Introduction}

A compelling force in medicine has always involved the human drive to feel better. An important part of feeling better concerns psychopharmacology, the treatment of disorder of mind and mood. Man has always search for the herb that heals the body and soothes the mind. The major merits of herbal medicine seem to be their perceived efficacy, low incidence of serious adverse effects and comparatively low cost. In most of the cultures, medicine has included the search for the enlightenment or higher meaning through the use of sacramental plants. Dioscorea bulbifera Linn. (family Dioscoreaceae) commonly known as varahikanda is an aerial yam cultivated in the South East Asia, West Africa, South and Central America. It is common throughout India ascending up to 6,000 ft. in the Himalayas. ${ }^{1}$ Dioscorea bulbifera has found its importance in traditional medicine throughout the world due to its steroid saponins diosgenin served as precursors in the synthesis of sex hormones, cardiatonic glucosides, fertility control compounds, corticosteroids and anabolic agents. ${ }^{2}$ Dioscorea bulbifera is used as bitter, pungent, improve appetite and complexion, used in dyspesis, leucoderma, bronchitis, piles and tumours in Indian ayurvedic system of medicine. ${ }^{3}$ Ancient and modern literature on its medicinal use have indicated that its tubers have therapeutic benefits in nervous excitability, hysteria, senility, infertility, syphilis, hemorrhoids, dysentery, diarrhea, hormonal deficiency, colic, abdominal pain and cramps; promotes body weight, and soothes digestive organs. ${ }^{4}$ Phytochemical study litereature indicates that the steroidal sapogenins, clerodane diterpenoids, norclerodane diterpenoids, flavanoids, carotenoids and Phytoalexin compounds have been isolated from $D$. bulbifera. ${ }^{2}$ Also, unique phytochemistry of this plant enables it to synthesize both gold and silver nanoparticles. ${ }^{5,6}$ Dioscorea bulbifera L. has been reported for antihyperlipidemic, antitumor, antioxidant, anorexiant, analgesic, anti-inflammatory, plasmid curing, antidiabetic, antihyperglycemic, gastroprotective, anthelmintic and antibacterial activities. ${ }^{7-16}$ However, no scientific data are available for neuropharmacological activity of tubers of Dioscorea bulbifera. In the light of above information and folklore uses, present study was designed to evaluate neuropharmacological activity of Dioscorea bulbifera using various experimental models.

\section{Materials and methods}

\section{Animals}

Swiss mice (20-25g) of either sex bred in the central animal house facility of the institute were used. These animals were housed under standard conditions, maintained on a $12 \mathrm{~h}$ light/dark cycle and had free access to food and water up to the time of experimentation. The animals were acclimatized to the laboratory environment $1 \mathrm{~h}$ before the experiments. Animals were randomly distributed into groups 
of 6 animals each. The experiment was conducted during the light period $(08.00-16.00 \mathrm{~h})$. The protocol was approved by the Institutional Animal Ethical Committee (IAEC) (Protocol No. CPCSEA/IAEC/ ARCP/14-15/04) and conducted according to the guidelines of CPCSEA (Committee or the Purpose of Control and Supervision of Experiment on Animals).

Collection and authentification of plant material: The tubers of Dioscorea bulbifera were collected from Valsad, Gujarat.The tuber was identified and authenticated by a taxonomist of Department of Botany, Bansilal Amrutlal College of Agriculture, Anand, Gujarat. (Authentification no: BACA/GPB/1356/15). A herbarium was prepared and deposited in Pharmacognosy deparatment of A. R. College of Pharmacy, Vallabh Vidyanagar (Herbarium no: DP/DB01/21/ARGH-15).

Preparation of plant extract: Collected tubers of $D$. bulbifera were washed dried and grounded to fine powder. The air dried powdered drug was extracted with water and alcohol mixture (50:50) three times in Soxhlet apparatus for 6hours. Extract of the tubers was evaporated to dryness under pressure to get solid mass. Freshly prepared aqueous solution of dried hydroalcoholic extract of tubers of $D$. bulbifera (DBE) was used for various experimental models.

Preliminary phytochemical screening: The hydroalcoholic extract of the D. bulbifera tubers was tested for the presence of carbohydrates, proteins, alkaloids, flavonoids, glycosides, saponins, tannins, and essential oils using standard procedures. ${ }^{16}$

\section{Drugs}

Diazepam (Calmpose injection, Ranbaxy, India) was used as standard drug (positive control) for spontaneous motor, muscle relaxant, exploratory, and anxiolytic activities. Sodium Pentobarbital (Sigma, St. Louis, MO, USA) was used to induce hypnosis in mice.

\section{Behavioral profile}

A systemic, quantitative procedure assessing the behavioural state of mice for the evaluation of drugs has been described by Irwin (1964, 1968). ${ }^{18}$ Mice were fasted for overnight and had water ad libitum. Extract was suspended in normal saline and was administered orally and to group of animals $(\mathrm{n}=3)$ in ascending order of and widely spread doses $(10,30,100,300,500 \& 1000 \mathrm{mg} / \mathrm{kg})$. One group was given vehicle which served as a control group. Immediately after drug administration, animals were closely observed for two hour, frequently for next four hrs. The parameters observed were spontaneous motor activity, touch, pain, motor co-ordination, grooming behaviour, convulsions, righting reflex, pinna reflex, corneal reflex, pupil size and muscle tone. The parameters observed were compared to the vehicle control group. The numbers of deaths were recorded after $24 \mathrm{hrs} .{ }^{19}$

\section{Treatment}

Based on behavioral test, two doses of DBE $(100 \mathrm{mg} / \mathrm{kg}$, p.o. and $300 \mathrm{mg} / \mathrm{kg}$, p.o.) were selected for the neuropharmacological activity. For each test, animals were divided in to five groups each group consisting of six animals. Group 1 served as control group received normal saline as vehicle $(1 \mathrm{ml} / \mathrm{kg})$ per oral, group 2 served as positive control received Diazepam ( $2 \mathrm{mg} / \mathrm{kg}$, i.p.). Group 3 and 4 served as test groups received DBE $100 \mathrm{mg} / \mathrm{kg}$, p.o. and $300 \mathrm{mg} / \mathrm{kg}$, p.o. respectively. One hour after oral and 30min after intraperitoneal administration, each animal was submitted to various neuropharmacological testing.

Spontaneous motor activity: The spontaneous motor activity was measured using an actophotometer. The movement of the animal cuts off a beam of light falling on the photocell and a count was recorded and displayed digitally. Each mouse was placed individually in the actophotometer for $10 \mathrm{~min}$ and basal activity score was obtained. ${ }^{20}$ After treatments mentioned as above, mice were placed again in the actophotometer for the recording the activity scores at 30,60 and 120 minutes.

Effect on motor co-ordination: This test was performed using a horizontal rotating rod set at a rate of 16 revolutions per minute. Mice that were able to remain on the rod longer than $3 \mathrm{~min}$ were selected. Mice were again placed on the rota-rod at 30,60 and 120minutes after treatments mentioned as above. The length of time taken before the animal fall from the rod during the $3 \mathrm{~min}$ trial was recorded in seconds. ${ }^{20}$

Pentobarbitone induced hypnosis: Pentobarbitone sodium (35mg/ $\mathrm{kg}$, i.p.) was administered to all pretreated animals. The time since the injection up to the loss of righting reflex was recorded as onset of sleep and the time elapsed between the loss and voluntary recovery of the righting reflex was recorded as duration of sleeping. ${ }^{20}$

\section{Anxiolytic activity}

Elevated plus maze test in mice: The elevated plus maze used in this study was modified from the one described by Lister (1987). ${ }^{21}$ The plus maze consisted of two opposite arms, $25 \mathrm{~cm} \times 5 \mathrm{~cm}$, crossed with two closed arms of the same dimensions with $30 \mathrm{~cm}$-high walls. The arms were connected with a central square, $7.5 \mathrm{~cm} \times 7.5 \mathrm{~cm}$, to give the apparatus the shape of a plus sign. The whole apparatus was elevated $25 \mathrm{~cm}$ above the floor in a dimly illuminated room. When exposed to this novel maze alley, the animals experienced an approach-avoidance conflict, which was stronger in the open arms than in the enclosed arms. Animals were placed individually in the center of the maze, facing a closed arm, after which the number of entries and time spent in the enclosed and open arms were recorded during the next five minutes. An arm entry was defined as the presence of all four feet in that particular arm. A selective increase in open arm exploration was observed as a consequence of anxiolytic drug administration. The maze was cleaned after each trial to remove any residue or odor of the animals. Each mouse was assessed individually after 30,60 and 120 minutes of administration of drugs. ${ }^{22}$

\section{Exploratory activity}

Head dip test: Exploratory activity was measured using the hole board apparatus. This study was conducted using wooded apparatus with 16 evenly spaced holes. Mice were grouped into 4 of 6 mice each. Mice were again placed on hole board at 30,60 and 120minutes after treatments mentioned as above. The number of head dips in to hole by each mouse during $5 \mathrm{~min}$ period was noted. ${ }^{20}$ Results were expressed as means for the various treatment groups at different time intervals.

Rectal temperature in mice : Rectal temperature of mouse was measured with digital thermometer connected with a thermoelectric probe, which was carefully inserted into the rectum of the animals about $2 \mathrm{~cm}$ depth. Temperature was recorded just before $\left(\mathrm{T}_{0}\right)$ and at $30,60,90$ and 120 minutes $\left(\mathrm{T}_{30}, \mathrm{~T}_{60}, \mathrm{~T}_{90} \& \mathrm{~T}_{120}\right.$ respectively) after treatments (for groups 1,3,4) in mice. ${ }^{20}$

\section{Statistical Analysis}

Results were expressed as mean (s) \pm S.E.M. The statistical 
significance of the difference between groups for the various treatments were determined by one way analysis of variance (ANOVA) followed by Dennett's test. $\mathrm{P}<0.05$ was considered statistically significant as compared to control.

\section{Results}

\section{Behavioral profile}

Results of behavioral test are shown in Table 1. There was decreased in locomotor activity and rearings. The animals were hyporeactive to external stimuli like touch and pain. Tremors, twitches, convulsions, straub tail response, lacrimations and loss of righting reflex were not observed. However, extract did not cause muscle weakness, or abnormal body posture and stereotypy at a dose that markedly decreased the locomotor activity. Signs of depression, reduced alertness and passivity were observed after the administration of DBE 100 and $300 \mathrm{mg} / \mathrm{kg}$ doses. No lethal effects were observed within $24 \mathrm{~h}$ after the administration of the DBE at any of the doses tested, even at the dose of $1000 \mathrm{mg} / \mathrm{kg}$. Thus, suggesting that oral route of administration is adequate and secure to produce its neuropharmacological effects and hence, the dose levels of 100 and $300 \mathrm{mg} / \mathrm{kg}$ body weight were chosen for the pharmacological screening.

Table I Effect of hydroalcoholic extract of Dioscorea bulbifera on behavioral profile of mice

\begin{tabular}{|c|c|c|c|c|c|c|c|}
\hline \multirow[t]{2}{*}{ Sr. No } & \multirow[t]{2}{*}{ Behavioral profile } & \multirow[t]{2}{*}{ Parameters } & \multicolumn{5}{|c|}{ Effect of DBE observed for $2 \mathrm{Hrs} .(\mathrm{Mg} / \mathrm{Kg})$} \\
\hline & & & 10 & 30 & 100 & 300 & 1000 \\
\hline \multirow[t]{3}{*}{ I } & Awareness & Alertness & & & $\downarrow$ & $\downarrow$ & $\downarrow$ \\
\hline & & Passivity & - & - & $\downarrow$ & $\downarrow$ & $\downarrow$ \\
\hline & & Stereotypy & - & - & - & - & - \\
\hline \multirow[t]{3}{*}{2} & Mood & Grooming & - & - & - & - & - \\
\hline & & Restlessness & - & - & - & - & - \\
\hline & & Irritability & - & - & - & - & - \\
\hline \multirow[t]{3}{*}{3} & Motor activity & Spontaneous activity & - & - & $\downarrow$ & $\downarrow$ & $\downarrow$ \\
\hline & & Touch response & - & - & $\downarrow$ & $\downarrow$ & $\downarrow$ \\
\hline & & Pain response & - & - & $\downarrow$ & $\downarrow$ & $\downarrow$ \\
\hline \multirow[t]{3}{*}{4} & CNS excitation & Tremors & - & - & - & - & - \\
\hline & & Convulsions & - & - & - & - & - \\
\hline & & Straub tail & - & - & - & - & - \\
\hline 5 & Posture & Body posture & - & - & - & - & - \\
\hline \multirow[t]{2}{*}{6} & Motor incoordination & Righting reflex & - & - & - & - & - \\
\hline & & Abnormal gait & - & - & - & - & - \\
\hline \multirow[t]{3}{*}{7} & Muscle tone & Grip strength & - & - & - & - & - \\
\hline & & Body tone & - & - & - & - & - \\
\hline & & Abnormal tone & - & - & - & - & - \\
\hline \multirow[t]{2}{*}{8} & Reflexes & Pinna & - & - & - & - & - \\
\hline & & Corneal & - & - & - & - & - \\
\hline \multirow[t]{3}{*}{9} & Autonomic & Writhing reflex & - & - & - & - & - \\
\hline & & Skin colour & - & - & - & - & - \\
\hline & & Pupil size & - & - & - & - & - \\
\hline 10 & Miscellaneous & Lacrimation & - & - & - & - & - \\
\hline II & Dead & No. of acute & Nil & Nil & Nil & Nil & Nil \\
\hline & & No. of delayed & Nil & Nil & Nil & Nil & Nil \\
\hline
\end{tabular}

$\downarrow$ indicate decrease, - indicate no change. 


\section{Spontaneous motor activity}

As shown in the Figure 1, the DBE (100 and 300mg/kg, p.o.) produced a significant $(\mathrm{P}<0.05)$ and dose dependent decrease in spontaneous motor activity. Similarly, positive control diazepam $(2 \mathrm{mg} / \mathrm{kg}$, i.p.) also produced significant reduction in spontaneous motor activity.

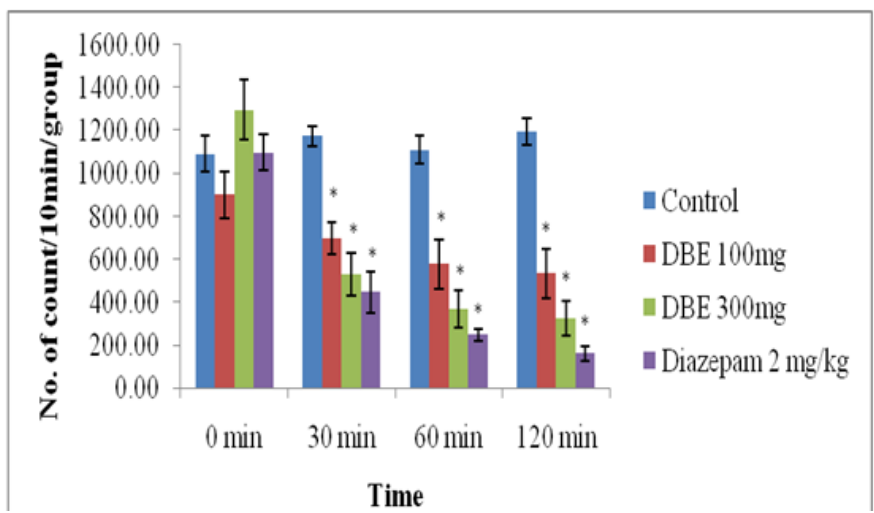

Figure I Effect of hydroalcoholic extract of Dioscorea bulbifera (DBE) on spontaneous motor activity in mice. Each bar represent the mean \pm SEM $(n=6)$. One way ANOVA followed by Dunnett's test, ${ }^{*} p<0.05$ when compared with control group.

\section{Effect on motor co-ordination}

No significant alteration was observed on rota rod test after 30,60 and $120 \mathrm{~min}$. of the oral administration of DBE at both the doses $(100$ and $300 \mathrm{mg} / \mathrm{kg}$, p.o.) tested. All the mice treated with this extract were stayed on rotating rod for more than 180 seconds without falling.

\section{Anxiolytic activity}

Elevated plus maze test in mice: As shown in Figure 2 and Figure 3 , DBE at $100 \mathrm{mg} / \mathrm{kg}$ and $300 \mathrm{mg} / \mathrm{kg}$ doses significantly increased the number of entries and the time spent in the open arms as compared with control. However, result was significant at $60 \mathrm{~min}$ after treatment with $100 \mathrm{mg} / \mathrm{kg}$ DBE treatment. Whereas, significant effect was observed at 30,60 and 120minutes after treatments with $300 \mathrm{mg} /$ $\mathrm{kg}$ dose of DBE. Also, Positive control, Diazepam (0.5mg/kg, i.p.) significantly increased the number of entries in the open arms as well as duration of stay in open arms, indicating anxiolytic activity.

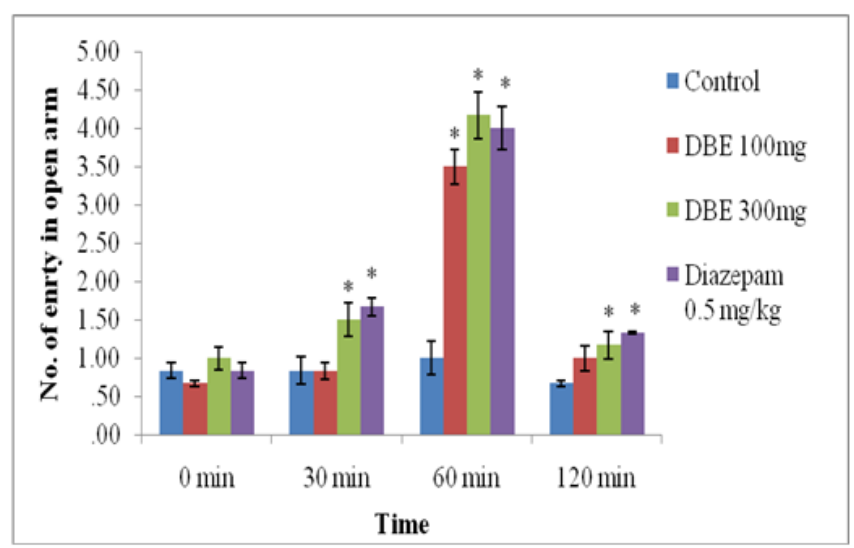

Figure 2 Effect of hydroalcoholic extract of Dioscorea bulbifera (DBE) on anxiolytic activity using elevated plus maze (Total number of entries in open arm). Each bar represent the mean \pm SEM. $(n=6)$. One way ANOVA followed by Dunnett's test, ${ }^{*} p<0.05$ when compared with control group.

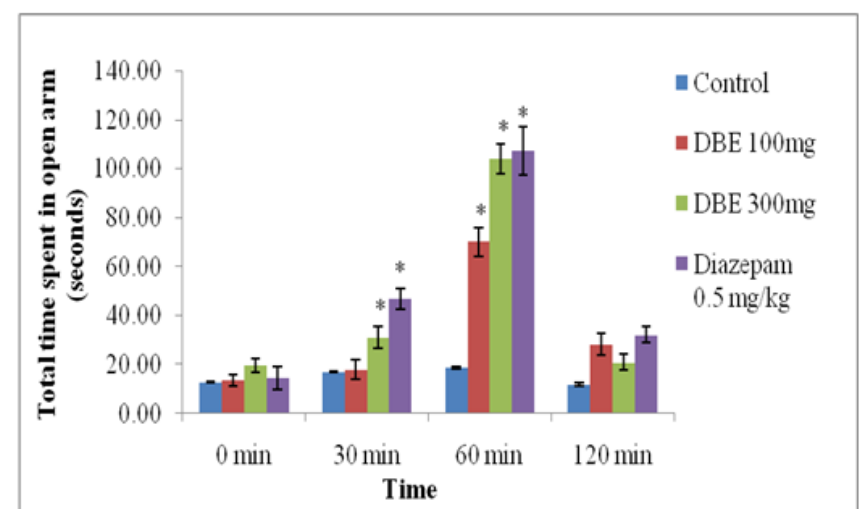

Figure 3 Effect of hydroalcoholic extract of Dioscorea bulbifera (DBE) on elevated plus maze (total time spent in open arm). Each bar represent the mean \pm SEM. $(n=6)$. One way ANOVA followed by Dunnett's test, ${ }^{*} p<0.05$ when compared with control group.

Head dip test: As shown in the Figure 4, DBE (100 and 300mg/ $\mathrm{kg}$, p.o.) produced reduction of exploratory activity as indicated by significant $(\mathrm{P}<0.05)$ and dose dependent decrease in the number of head dips. Similarly, Diazepam caused a significant decrease in the number of head dips.

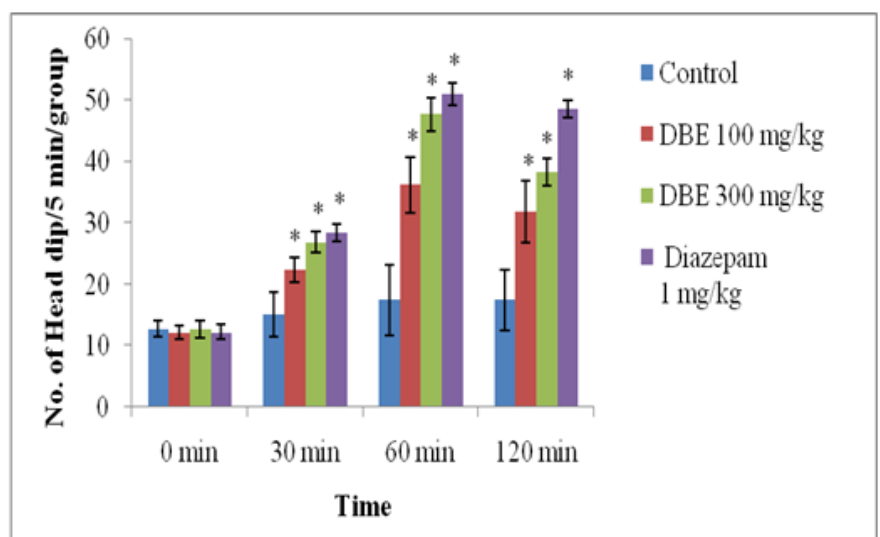

Figure 4 Effect of hydroalcoholic extract of Dioscorea bulbifera (DBE) on exploratory activity by head dip test. Each bar represent the mean \pm SEM. $(n=6)$. One way ANOVA followed by Dunnett's test, * $p<0.05$ when compared with control group.

Pentobarbitone induced hypnosis: The results of the effect of DBE on sleeping latency and duration of pentobarbital sleep are presented in Figure 2. The DBE $(100 \mathrm{mg} / \mathrm{kg}$, p.o.) significantly prolonged the duration of pentobarbital sleeping time in mice without affecting onset of pentobarbital induced sleep. However, DBE in the dose of $300 \mathrm{mg} / \mathrm{kg}$ significantly reduced onset and prolonged duration of pentobarbital sleeping time. Standard treatment also produced simlar results.

Rectal temperature in mice: The rectal temperature of mice was recorded at $0,30,60,90$ and 120 min after treatments. As shown in Figure 5, Figure 6 in control animals, there was no significant variations on rectal temperature were observed. However, on treatment with the DBE at the dose of $100 \mathrm{mg} / \mathrm{kg}$ produced significant fall in rectal temperature of mice at $60 \mathrm{~min}$ whereas $300 \mathrm{mg} / \mathrm{kg}$ dose produce a significant fall in rectal temperature at 30,60 and 120minutes after treatment. 


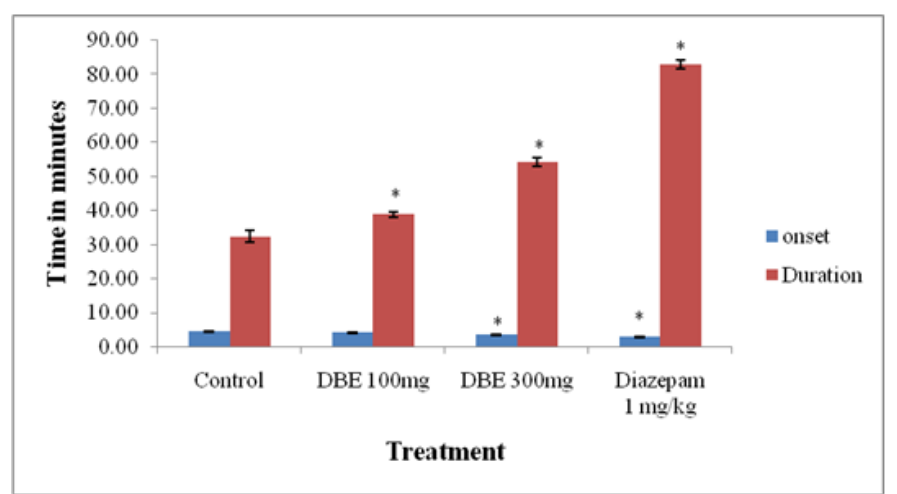

Figure 5: Effect of hydroalcoholic extract of Dioscorea bulbifera (DBE) pentobarbital $(35 \mathrm{mg} / \mathrm{kg}$, i.p.) induced hypnosis in mice. Each bar represent the mean \pm SEM. $(n=6)$. One way ANOVA followed by Dunnett's test, * $p<0.05$ when compared with control group.

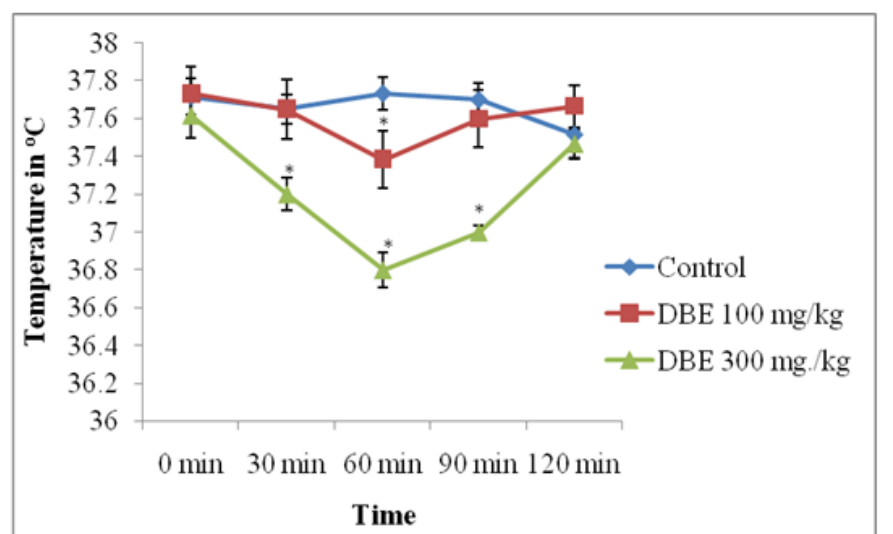

Figure 6 Effect of hydroalcoholic extract of Dioscorea bulbifera (DBE) on rectal temperature. Each bar represent the mean \pm SEM. $(n=6)$. One way ANOVA followed by Dunnett's test, ${ }^{*} p<0.05$ when compared with control group.

\section{Discussion}

In this work, the neuropharmacological effects of the hydroalcoholic extract of Dioscorea bulbifera tubers (DBE) were studied in several behavioral animal models for the evaluation of their possible neuropharmacological activity. The results of the present investigation showed that the hydroalcoholic extract of $D$. bulbifera tubers has some potent neuropharmacological activity. Assessment of behavioural profile and toxicity is the first step in the toxicological investigation of an unknown substance. The hydroalcoholic extract of $D$. bulbifera tubers was well tolerated by mice and there were no signs of acute (during $2 \mathrm{~h}$ observation period) or delayed $(24 \mathrm{~h}$ after extract treatment) toxicity after oral administration. Increasing doses of the D. bulbifera tubers up to $1 \mathrm{~g} / \mathrm{kg}$ (p.o.) were not lethal, the LD50 values for the extract was estimated to be higher than $1 \mathrm{~g} /$ $\mathrm{kg}$ for oral administration. Thus, suggesting that this administration route is adequate and secure to produce its neuropharmacological effects. The spontaneous motor activity is a measure of the gross motor activity of the animal, and reflects the integrity of the entire neuromuscular system and its control and regulation by the central nervous system. Reduction in the spontaneous motor activity leads to sedation ${ }^{23}$ as a result of reduced excitability of the central nervous system. Many groups of psychotropic agents including antipsychotics, anticonvulsants, antidepressants, and narcotic analgesics, can diminish spontaneous motor activity in all species of animals including humans. Prolongation of pentobarbital hypnosis was due to sedative and/or hypnotic property attributed to an action on the central mechanisms involved in the regulation of sleep or an inhibition of pentobarbital metabolism. ${ }^{20,24}$ The hydroalcoholic extract of $D$. bulbifera tubers significantly reduced spontaneous motor activity and prolonged pentobarbital induced hypnosis in mice. Thus, suggesting that the hydroalcoholic extract of $D$. bulbifera tubers might be acting as mild neurosedative / CNS depressant agents.

The elevated plus maze is considered to be an etiologically valid animal model of anxiety. Number of entries and time spent in the open arms have been found to be increased by anxiolytics and reduced by anxiogenic agents. ${ }^{25}$ In this test, DBE increased the entries into and time spent in the open arms, indicating an anxiolytic-like effect without motor impairment. These results indicate that anxiolytic activity is comparable with that produced by diazepam. As expected, diazepam reduced the animal's natural aversion to the open arms and promoted maze exploration..$^{22}$ Despite the good predictive validity of the elevated-plus-maze and test for anxiolytic-like drugs, the use of more than one animal model of anxiety is recommended to avoid falsepositive results. The head dip test can be used to confirm the anxiolyticlike effect observed in the elevated-plus-maze test. Hole Board test is a measure of exploratory behavior ${ }^{26}$ and an agent that increases this behavior reveals anxiolytic ${ }^{26}$ activity. On the other hand, a decrease in the number of head-dipping reveals a depressant behavior. ${ }^{20}$ The hydroalcoholic extract of $D$. bulbifera tubers increased exploratory behavior in the hole board test, further confirming anxiolytic nature of $D$. bulbifera tubers. Reduction in the rectal temperature of mice by $D$. bulbifera tubers extract treatment also indicated probable central nervous depressant action. ${ }^{20}$ Furthermore, the inability of the hydroalcoholic extract of $D$. bulbifera tubers to affect motor coordination is additional evidence of centrally mediated actions and not blockade of neuromuscular system. ${ }^{20}$ The efficacy of most herbal remedies is attributed to various active principles in combination. Results of phytochemical screening showed presence of terpenoids, saponins, flavanoids, alkaloids, glycosides, carbohydrates, amino acids, and proteins in the tubers which may lead to CNS depressant/ sedative or anxiolytic activity of the plant. In conclusion, the results of present study provide evidence that the hydroalcoholic extract of D. bulbifera tubers may contain some psychoactive principles, which are sedative and anxiolytic in nature. This study provides scientific evidence for the traditional medicinal use of this plant in nervous disorders.

\section{Acknowledgements}

None.

\section{Conflict of interest}

The author declares no conflict of interest.

\section{References}

1. The Wealth of India. Raw materials. New Delhi: CSIR; 1998;4:67-76.

2. Ghosh S, Parihar VS, More P, et al. Phytochemistry and therapeutic potential of medicinal plant: Dioscorea bulbisdfera. Med chem. $2015 ; 5: 160-172$.

3. Kirtikar KR, Basu BD, ICS. Indian Medicinal Plants. 2nd ed. International book distributorspp; 2007;4:2452-2456. 
4. Uniyal RC. The Ayurveda Encyclopedia Natural Secrets to Healing, Prevention \& Longevity. 1st ed. USA: Ayurveda Holistic Center Press; 1998. p. 108-109.

5. Ghosh S, Patil S, Ahire M, et al. Synthesis of silver nanoparticles using Dioscorea bulbifera tuber extract and evaluation of its synergistic potential in combination with antimicrobial agents. Int $J$ Nanomedicine. 2012;7:483-496.

6. McKoy ML, Omoruyi F, Simon O, et al. Investigation of the effects of a sapogenin-rich preparation from a Jamaican yam (Dioscorea sp.) on blood cholesterol levels in rats. Proc West Pharmacol Soc. 2013;46:156159.

7. Gao H, Kuroyanagi M, Wu L, et al. Antitumor-promoting constituents from Dioscorea bulbifera L. in JB6 mouse epidermal cells. Biol Pharm Bull. 2002;25(9):1241-1243.

8. Bhandari MR, Kawabata J. Organic acid, phenolic content and antioxidant activity of wild yam (Dioscorea spp.) tubers of Nepal. Food Chem. 2004;88:163-168.

9. Jindal MN, Kelkar VV, Doctor RB. The anorexient activity of Kaliokund (Dioscorea bulbifera Linn.), methylphenidate and cocaine in rats:a preliminary study. Indian J Med Res. 1969;57(6):1075-1080.

10. Nguelefack TB, Dutra RC, Paszcuk AF, et al. Antinociceptive activities of the methanol extract of the bulbs of Dioscorea bulbifera L. var sativa in mice is dependent of NO-cGMP-ATP-sensitive- $\mathrm{K}(+)$ channel activation. J Ethnopharmacol. 2010;128(3):567-574.

11. Shriram V, Jahagirdar S, Latha $C$, et al. A potential plasmid-curing agent, 8-epidiosbulbin E acetate, from Dioscorea bulbifera L. against multidrug-resistant bacteria. Int J Antimicrobial Agents. 2008;32(2):405-410.

12. Ahmed Z, Chishti MZ, Johri RK, et al. Antihyperglycemic and antidyslipidemic activity of aqueous extract of D. bulbifera tubers. Diabetologia Croatica. 2009;38:63-72.

13. Balasubramanian J, Dhanalakshmi R, Jibnomen P, et al. A preclinical evaluation on antioxidant and gastroprotective effect of Dioscorea bulbifera in wistar rats. Indian J of Innovation and Discovery. 2012;1(3):1-8.

14. Adeniran AA, Sonibare MA. In vitro potential anthelmintic activity of bulbils of Dioscorea bulbifera L. on earthworms and liverflukes. J Pharmacognosy Phytother. 2013;5(12):196-203.
15. Okigbo RN, Anuagasi CL, Amadi JE, et al. Potential inhibitory effects of some African tuberous plant extracts on Escherichia coli, Staphylococcus aureus and Candida albicans. Int J Integrat Biol. 2009;6:91-98.

16. Kokate CK, Purohit AP, Gokhale SB. Practical in pharmacognosy. 31st edn. Nirali Prakashan, Pune, India; 2006. p. 105-114.

17. Irwin S. Drug screening evaluative procedures. Science. 1962;136:123126.

18. Turner RA. Screening Methods in Pharmacology. 1st edn. Noida: Elsevier; 2009. p. 26

19. Galani VJ, Patel BG. Psychotropic activity of Argyreia speciosa roots in experimental animals. AYU. 2011;32(3):380-384.

20. Lister RG. The use of a plus-maze to measure anxiety in the mouse. Psychopharmacol. 1987;92(2):180-185.

21. Galani VJ, Patel BG. Effect of hydroalcoholic extract of Sphaeranthus indicus against experimentally induced anxiety, depression and convulsions in rodents. Int J Ayu Res. 2010;1(2):87-92.

22. Parshad O, Young LE and Young RE. Young Neem (Azadirachta indica) treatment decreases spontaneous motor activity in rats:implications for its central sedative action. Phytotherapy Res. 1997;11(5):398-400.

23. Fujimori H. Potentiation of barbital hypnosis as an evaluation method for central nervous system depressant. Psychopharmacol. 1965;7(5):347377.

24. Pellow S, Chopin P, File SE, et al. Validation of open, closed arm entries in an elevated plus-maze as a measure of anxiety in the rat. $J$ Neurosci Meth. 1985;14(3):149-167.

25. File S, Wardill AG. Validity of head-dipping as a measure of explorating a modified hole-board. Psychopharmacologia. 1975;44(1):53-59.

26. Vázquez MM, Reyes RE, Laurrabaquio AM, et al. Neuropharmacological study of Dracocephalum moldavicaL. (Lamiaceae) in mice: Sedative effect and chemical analysis of an aqueous extract. J of Ethnopharmacology. 2012;141(3):908-917. 